\title{
Molecular detection and characterisation of avian paramyxovirus type 1 in backyard chickens and pigeons in Alzintan city of Libya
}

\author{
Abdulwahab Kammon ${ }^{1, *}$, Isabella Monne ${ }^{2}$, Abdulatif Asheg ${ }^{1}$ and Giovanni Cattoli ${ }^{2}$ \\ ${ }^{1}$ Faculty of Veterinary Medicine, University of Tripoli, P.O. Box 13662, Tripoli, Libya \\ ${ }^{2}$ Istituto Zooprofilattico Sperimentale delle Venezie, Viale dell'Universita, 10, Legnaro, Padova 35020, Italy
}

\begin{abstract}
Avian paramyxovirus-1 (APMV-1) is the causative agent of Newcastle Disease which affects many species of birds leading to high mortality and heavy economic losses among poultry industry worldwide. Newcastle disease is endemic in Libya with frequent outbreaks occurring in commercial and backyard poultry. APMV-1 was isolated and characterised during the outbreak in 2013. In current study, we report another Newcastle disease outbreak that emerged in backyard chickens and pigeons in Alzintan city on March 2015. Two viruses were detected in cloacal swabs from backyard chickens, namely APMV-1/Libya/15VIR5368/2015 and APMV-1/Libya/15VIR5371/2015. Genetic sequencing of these viruses revealed the presence of velogenic APMV-1 belonging to genotype VIIi genetically similar to the viruses isolated on 2013. During the same period, neurologic signs and mortality were noticed in pigeons. Samples of brain tissue were tested by rRT-PCR which revealed presence of velogenic APMV-1 belonging to lineage 4A (GKKRKR*F Lin.4A) or genotype VIb. To the best of our knowledge, this is the first report of the detection and molecular characterization of APMV-1 in a pigeon in Libya. The phylogenetic analysis of the F gene showed 86\% identity to isolates from Iran and Egypt. This study may indicate the circulation of APMV-1 within backyard birds and pigeons which may present a threat to commercial poultry. Considering these findings, vaccination of backyard birds and pigeons and further epidemiological studies are strongly strongly recommended.
\end{abstract}

Keywords: Alzintan city, Avian Paramyxovirus-1, Molecular characterization, Newcastle disease, Phylogenetic analysis.

\section{Introduction}

Avian paramyxovirus-1 (APMV-1) is the causative agent of Newcastle Disease (ND) which affects many species of birds leading to high mortality and heavy economic losses among poultry industry worldwide. Rapid detection and assessment of the virulence of Newcastle disease virus (NDV) is essential to ensure that outbreaks are contained and their impact is minimized. Although different genotypes of APMV-1 circulate in many parts of the world, they all belong to a unique APMV-1 serotype.

Since 1926 and based on nucleotide sequences, nine class I APMV-1 and 10 distinct lineages of class II APMV-1 (I to IX and XI) strains have been identified (Czegle'di et al., 2006; Kim et al., 2007). Genotypes V, VI, and VII of virulent viruses are the predominant genotypes circulating worldwide (Miller et al., 2010); of these, genotype VII is particularly important given that it has been associated with many of the most-recent outbreaks in Asia, Africa, and the Middle East (Liu et al., 2003; Kim et al., 2007; Khan et al., 2010).

Chickens infected with NDV may show clinical signs varying from extremely mild respiratory or enteric disease (avirulent viruses) to severe systemic infection, resulting in high mortality (virulent viruses) and characterized by very rapid spread (Alexander, 2001). Newcastle disease is endemic in Libya with frequent outbreaks occurring in commercial and backyard poultry. In March 2013, the Libyan poultry industry faced a severe outbreak caused by ND.

APMV-1 was isolated and characterized. Following detection of the virus in allantoic fluid by rRT-PCR, genetic sequencing of the APMV1/chicken/Libya/13VIR/7225-1/2013 isolate revealed the presence of a velogenic APMV-1 belonging to lineage 5 (GRRRQKR*F Lin.5) or genotype VIIi in class II, according to the nomenclature in use.

The use of live attenuated and inactivated vaccines in commercial poultry had significantly reduced the impact of the disease (Kammon et al., 2015).

Molecular characterization and monitoring is very important for the epidemiologic studies required in the development and adaptation of control strategies.

In this study the $\mathrm{F}$ gene sequence of the APMV1/Libya/15VIR5368/2015, APMV1/Libya/15VIR5371/2015 and APMV1/Libya/15VIR5369/2015 were obtained and a phylogenetic tree was constructed. Furthermore, this is the first report describing the APMV-1 identified in pigeon in Libya. 


\section{Materials and Methods}

\section{Samples}

In March 2015, high mortality and sudden death were reported in backyard chickens and pigeons in Alzintan city located at the west region of Libya. The clinical details are presented in table 1. Cloacal swabs were collected from 3 backyard chickens and gently streaked on FTA ${ }^{\circledR}$ cards (Sigma-Aldrich, St. Louis, MO). The necropsies were conducted on dead chickens and pigeons and appropriate samples were collected. Brain tissue of a pigeon was also streaked on $\mathrm{FTA}^{\circledR}$ cards. All FTA-cards were labelled, air-dried, stored in $-20^{\circ} \mathrm{C}$ and later sent to the F.A.O./O.I.E. reference laboratory, the Istituto Zooprofilattico Sperimentale delle Venezie, Italy (IZSVe).

\section{Molecular detection and characterization}

After extraction of RNA, FTA cards were examined for APMV-1 and Avian influenza type A viruses (AIV) by real-time reverse transcription-PCR (rRT-PCR) using a commercial kit (AnDiatec, Kornwestheim, Germany) and using the real-time protocol as previously described (Spackman et al., 2002; Cattoli et al., 2009). Samples testing positive for APMV-1, were sent to the IZSVe for genetic sequencing. Viral RNA was extracted using the Nucleospin RNA II kit (Machery-Nagel, Duren, Germany). Following amplification with rRT-PCR (Wise et al., 2004), amplicons were sequenced using the BigDyeH Terminator v3.1 cycle sequencing kit (Applied Biosystems, Foster City, CA). The products were cleaned using Performa DTR Ultra 96-Well kit (Edge BioSystems, Gaithersburg, MD) and sequenced in a 16-capillary ABI PRISMH 3130 xl Genetic Analyzer (Applied Biosystems). Nucleotide sequences were aligned and phylogenetic analysis was performed using the neighbor-joining method in the Molecular Evolutionary Genetics Analysis (MEGA5) program (Tamura et al., 2011). The analysis was conducted using the maximum composite likelihood method in MEGA5. Codon positions included were $1^{\text {st }}, 2^{\text {nd }}, 3^{\text {rd }}$, and noncoding. All positions containing gaps and missing data were eliminated. The rate variation among sites was modeled with a gamma distribution (shape parameter $=1.29$ ). The differences in the composition bias among sequences were considered in evolutionary comparisons.

\section{Results and Discussion}

All tested samples were negative for Avian Influenza Virus (AIV) using real time PCR but three of them were positive for APMV-1. In backyard chickens, two viruses were detected in cloacal swabs namely APMV1/Libya/15VIR5368/2015 and APMV1/Libya/15VIR5371/2015. The third cloacal swab collected from the backyard White Leghorn chicken was negative for APMV-1. Sample of brain tissue collected from the pigeon was tested positive for APMV-1 by rRT-PCR. Partial sequence analysis of the
F gene showed that all three tested isolates has multiple basic amino acids at the cleavage site, with the phenylalanine at amino acid (aa) position 117 at the $\mathrm{N}$ terminus of the $\mathrm{F} 1$ protein. The viruses detected in the samples numbered 15VIR5368/2015 and 15VIR5371/2015 in backyard chickens revealed velogenic APMV-1 belonging to lineage $5 \mathrm{~A}$ (RRRQKR*F Lin.5A) or genotype VIIi. The virus detected in the pigeon was velogenic APMV-1 belonging to lineage $4 \mathrm{~A}$ (GKKRKR*F Lin.4A) or genotype $\mathrm{VIb}$. The partial sequence of the two viruses detected in backyard chickens presented a high similarity $(100 \%)$ with viruses identified in Libya during the 2013 outbreak (Fig. 1). The evolutionary distances between the monophyletic group formed by these viruses (bootstrap value 100\%) and class II genotypes were inferred. Based on the average distance per site, the Libyan virus was assigned to genotype VII. Based on genotyping guidelines (Diel et al., 2012), these viruses are related to the new subgenotype within genotype VII, which have been provisionally classified as subgenotype VIIi. APMV-1 genotype VII is particularly important given that it has been associated with many of the most recent outbreaks in Asia, Africa, and the Middle East (Liu et al., 2003; Kim et al., 2007; Khan et al., 2010).

Phylogenetic analysis of genome sequencing of these viruses, which has become a standard method in modern laboratories, revealed the presence of velogenic APMV-1 genetically similar to the virus isolated in 2013 (Kammon et al., 2015). All the tested isolates had multiple basic amino acids at the cleavage site, with the phenylalanine at amino acid (aa) position 117 at the $\mathrm{N}$ terminus of the F1 protein, which is a typical molecular marker of velogenic strains (Cattoli and Monne, 2009). The third cloacal swab collected from the backyard White Leghorn chicken was negative for APMV-1. It is previously reported that some chronic bacterial infections mainly fowl cholera may cause nervous signs such as torticollis in chickens (Glisson et al., 2008). However, bacterial isolation and identification was not attempted in this study.

During the same period, neurologic signs and mortality were noticed in pigeons. Samples of brain tissue collected from a pigeon were tested by rRT-PCR which revealed presence of velogenic APMV-1 (APMV1/Libya/15VIR5369/2015) belonging to lineage 4A (GKKRKR*F Lin.4A) or genotype VIb. To the best of our knowledge, this is the first report of the detection and molecular characterization of APMV-1 in pigeon in Libya. The phylogenetic analysis of the $\mathrm{F}$ gene showed $86 \%$ identity to the isolates LC055513/Iran/PPMV1-21/2014/Iran and LC055515/PPMV1-52CT/Iran/2014 isolated from pigeons in Ahfaz, Iran which belonged to genotype VI (Mayahi et al., 2017). 
Table 1. Case history and samples collected from chickens and pigeons in Alzintan city during Newcastle disease outbreak.

\begin{tabular}{|c|c|c|c|c|c|}
\hline $\begin{array}{l}\text { Poultry } \\
\text { species }\end{array}$ & Age & Clinical signs & Lesions & Sample ID & $\begin{array}{l}\text { Type of } \\
\text { samples }\end{array}$ \\
\hline $\begin{array}{l}\text { Backyard } \\
\text { chicken }\end{array}$ & Adult & $\begin{array}{l}\text { Dyspnea, bloody } \\
\text { diarrhoea, cyanotic } \\
\text { comb and wattles }\end{array}$ & $\begin{array}{l}\text { Severe enteritis with stripping areas of } \\
\text { haemorrhages }\end{array}$ & 15VIR5368 & $\begin{array}{l}\text { FTA card- } \\
\text { cloacal }\end{array}$ \\
\hline Pigeon & Adult & $\begin{array}{l}\text { Torticollis and tremors } \\
\text { of the neck }\end{array}$ & None & 15VIR5369 & $\begin{array}{l}\text { FTA card- } \\
\text { brain tissue }\end{array}$ \\
\hline $\begin{array}{l}\text { Layers (White } \\
\text { Leghorns) }\end{array}$ & Adult & Torticollis & Peritonitis, atresia of the ova & 15VIR5370 & $\begin{array}{l}\text { FTA card- } \\
\text { cloacal }\end{array}$ \\
\hline $\begin{array}{l}\text { Backyard } \\
\text { chicken }\end{array}$ & Adult & $\begin{array}{l}\text { Sudden death, greenish } \\
\text { diarrhea, excessive } \\
\text { salivation, swollen head } \\
\text { and sinusitis }\end{array}$ & $\begin{array}{l}\text { Enteritis, haemorrhages on cecal tonsils } \\
\text { and at the junction between proventriculus } \\
\text { and gizzard, slight tracheitis and congested } \\
\text { comb and wattles }\end{array}$ & 15VIR5371 & $\begin{array}{l}\text { FTA card- } \\
\text { cloacal }\end{array}$ \\
\hline
\end{tabular}

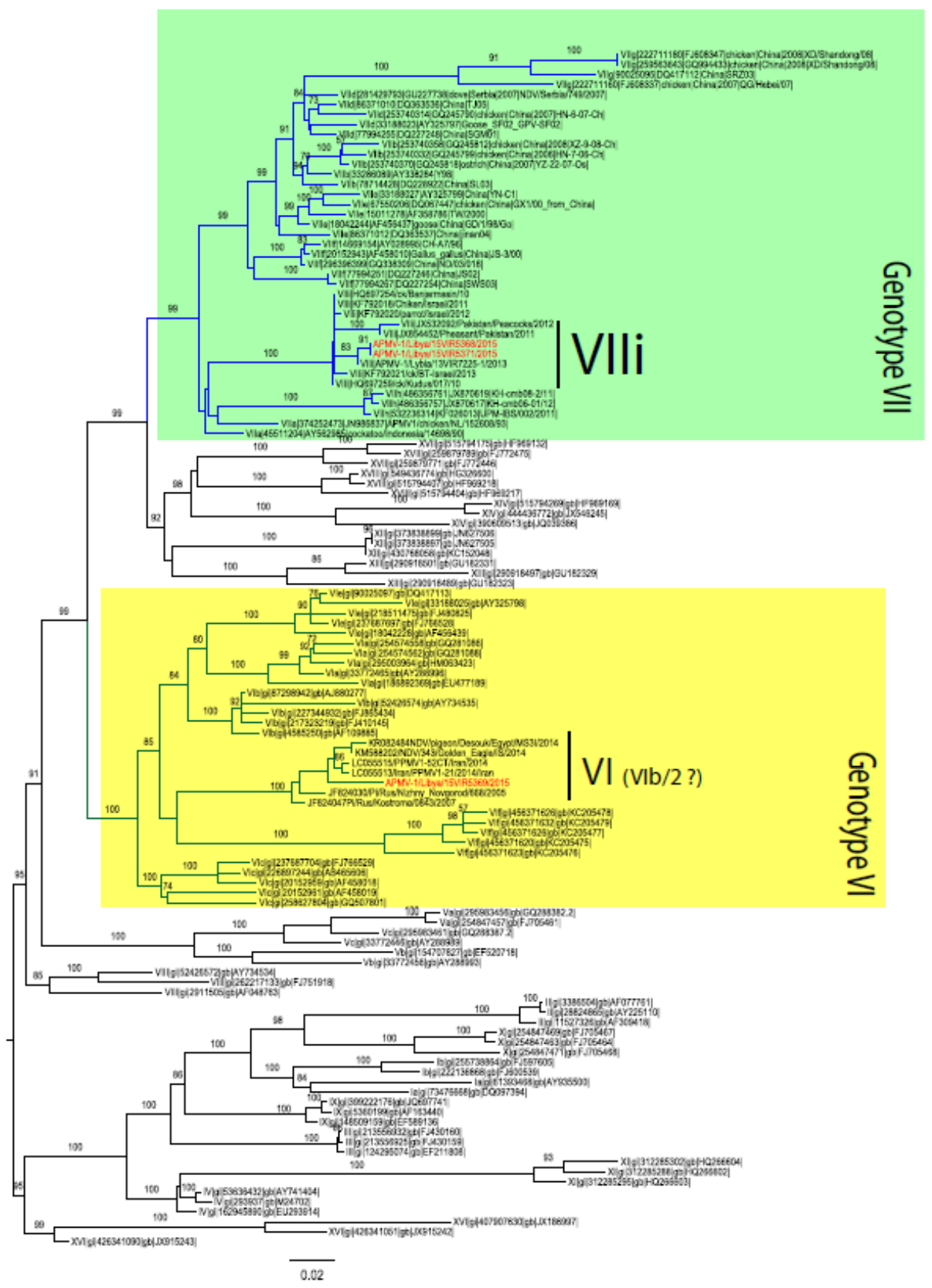

Fig. 1. Phylogenetic tree of APMV-1 complete F gene detected in backyard chickens and pigeons with a bootstrap value of 100. 
In Africa, Asia and Europe the most recovered isolated genotype of pigeon paramyxovirus type I (PPMV-1), is VI genotype (Liu et al., 2006; Abolnik et al., 2008; Smietanka and Minta, 2011; Bogoyavlenskiy et al., 2012). In support of our findings, the isolates belong to genotype VI often cause nervous signs in pigeons (Ujvari et al., 2003). The phylogenetic analysis of our isolate APMV-1/Libya/15VIR5369/2015 has also revealed identity to Egyptian isolate KR082484NDV/pigeon/Desouk/Egypt/MS31/2014 which was considered as the first pathotypic and genetic characterizations of PPMV-1 from pigeon in Egypt during 2014 (Rohaim et al., 2016). The virulence potential of genotype VI strains of PPMV1 in chickens is determined by virus strain, age of chickens, and the route of viral infections leading to mild respiratory to neurotropic disease and mortality (Toro et al., 2005). In conclusion, we report two velogenic strains of APMV1 in backyard chickens belonging to genotype VII similar to the one reported in 2013 and one velogenic strain of APMV-1 in pigeon belonging to genotype VIb for the first time in Libya. These findings were based on partial sequencing of the $\mathrm{F}$ gene allowing the comparative sequence analysis necessary to evaluate transmission routes and origins of outbreaks. There remains a need for more full-length genomes. Therefore, the extensive surveillance of the backyard and wild birds for APMV-1, is a fundamental requirement for understanding the epidemiology of these viruses and vaccination of backyard birds and pigeons is strongly recommended.

\section{Conflict of interest}

The authors declare that there is no conflict of interest.

\section{References}

Abolnik, C., Gerdes, G.H., Kitching, J., Swanepoel, S., Romito, M. and Bisschop, S.P. 2008. Characterization of pigeon paramyxoviruses (Newcastle disease virus) isolated in South Africa from 2001 to 2006. Onderstepoort J. Vet. Res. 75, 147-152.

Alexander, D.J. 2001. Newcastle disease. Br. Poult. Sci. 42(1), 5-22.

Bogoyavlenskiy, A., Berezin, V., Prilipov, A., Usachev, E., Korotetskiy, I., Zaitceva, I., Kydyrmanov, A. and Sayatov, M. 2012. Characterization of pigeon paramyxoviruses (Newcastle disease virus) isolated in Kazakhstan in 2005. Virol. Sin. 27 (2), 93-99.

Cattoli, G. and Monne, I. 2009. Chapter 11: Molecular diagnosis of Newcastle disease virus. In: Avian influenza and Newcastle disease: a field and laboratory manual. I. Capua and D. Alexander, eds. Springer Verlag, Italy.

Cattoli, G., De Battisti, C., Marciano, S., Ormelli, S., Monne, I., Terregino, C. and Capua, I. 2009. False- negative results of a validated real-time PCR protocol for diagnosis of Newcastle disease due to genetic variability of the matrix gene. J. Clin. Microbiol. 47, 3791-3792.

Czegle'di, A., Ujva'ri, D., Somogyi, E., Wehmann, E., Werner, O. and Lomniczi, B. 2006. Third genome size category of avian paramyxovirus serotype 1 (Newcastle disease virus) and evolutionary implications. Virus Res. 120, 36-48.

Diel, D.G., da Silva, L.H., Liu, H., Wang, Z., Miller, P.J. and Afonso, C.L. 2012. Genetic diversity of avian paramyxovirus type 1: proposal for a unified nomenclature and classification system of Newcastle disease virus genotypes. Infect. Genet. Evol. 12, 1770-1779.

Glisson, R.J., Hofacre L.C. and Christensen, P.J. 2008. Fowl Cholera. In: Saif, Y.M., Barnes, H.J., Glisson, J.R., Fadly, A.M., McDougald, D.J., Swayne, D.E. (Eds.), Diseases of Poultry. 12 $2^{\text {th }}$ ed. Iowa State Press, Ames, pp: 739-758.

Kammon, A., Heidari, A., Dayhum, A., Eldaghayes, I., Sharif, M., Monne, I., Cattoli, G., Asheg, A., Farhat, M. and Kraim, E. 2015. Characterization of Avian Influenza and Newcastle disease viruses from Poultry in Libya. Avian Dis. 59, 422-430.

Khan, S.T., Rehmani, R.C., Miller, P. and Afonso, C.L. 2010. Phylogenetic and pathological characterization of Newcastle disease virus isolates from Pakistan. J. Clin. Microbiol. 48, 1892-1894.

Kim, L.M., King, D.J., Suarez, D.L., Wong, C.W. and Afonso, C.L. 2007. Characterization of class I Newcastle disease virus isolates from Hong Kong live bird markets and detection using real-time reverse transcription-PCR. J. Clin. Microbiol. 45, 1310-1314.

Liu, H., Wang, Z., Song, C., Wang, Y., Bin, Yu, Zheng, B., Sun, C. and Wu, Y. 2006. Characterization of pigeon-origin Newcastle disease virus isolated in China. Avian Dis. 50, 636-640.

Liu, X.F., Wan, H.Q., Ni, X.X., Wu, Y.T. and Liu, W.B. 2003. Pathotypical and genotypical characterization of strains of Newcastle disease virus isolated from outbreaks in chicken and goose flocks in some regions of China during 1985-2001. Arch. Virol. 148, 1387-1403.

Mayahi, M., Masoud, R., Seyfi A., Shapouri, R., Ali J. and Mehrdad K.F. 2017. Characterization of isolated pigeon paramyxovirus-1 (PMV-1) and its pathogenicity in broiler chickens. Vet. Res. Forum 8(1), 15-21.

Miller, P.J., Decanini, E.L. and Afonso, C.L. 2010. Newcastle disease: evolution of genotypes and the related diagnostic challenges. Infect. Genet. Evol. 10, 26-35.

Rohaim, M.A., El-Naggar, R.F., Helal, A.M., Hussein, H.A. and Le-Blanc, N. 2016. Genetic 
characterization of pigeon paramyxovirus type 1 in Egypt. Br. J. Virol. 3(2), 27-32.

Smietanka, K. and Minta, Z. 2011. Isolation of an atypical pigeon paramyxovirus type 1 in Poland. Poland J. Vet. Sci. 14(1), 141-143.

Spackman, E., Senne, D.A., Myers, T.J., Bulaga, L.L., Garber, L.P., Perdue, M.L., Lohman, K., Daum, L.T. and Suarez, D.L. 2002. Development of a realtime reverse transcriptase PCR assay for type A influenza virus and the avian $\mathrm{H} 5$ and $\mathrm{H} 7$ hemagglutinin subtypes. J. Clin. Microbiol. 40, 3256-3260.

Tamura, K., Peterson, D., Peterson, N., Stecher, G., Nei, M. and Kumar, S. 2011. MEGA5: Molecular evolutionary genetics analysis using maximum likelihood, evolutionary distance, and maximum parsimony methods. Mol. Biol. Evol. 28, 2731-
2739.

Toro, H., Hoerr, F.J., Farmer, K., Dykstra, C.C., Roberts, S.R. and Perdue, M. 2005. Pigeon paramyxovirus: association with common avian pathogens in chickens and serologic survey in wild birds. Avian Dis. 49, 92-98.

Ujvari, D., Wehmann, E., Kaleta, E.F., Werner, O., Savić, V., Nagy, E., Czifra, G. and Lomniczi, B. 2003. Phylogenetic analysis reveals extensive evolution of avian paramyxovirus type 1 strains of pigeons (Columba livia) and suggests multiple species transmission. Virus Res. 96, 63-73.

Wise, M., Suarez, D., Seal, B., Pedersen, J., Senne, D., King, D., Kapczynski, D. and Spackman, E. 2004. Development of a realtime reverse-transcription PCR for detection of Newcastle disease virus RNA in clinical samples. J. Clin. Microbiol. 42, 329-338. 